\title{
Transesterification of Jatropha curcas crude oil to biodiesel on calcium lanthanum mixed oxide catalyst: effect of stoichiometric composition
}

\begin{abstract}
Heterogeneous solid mixed oxide (CaOï La2O3) catalysts with different molar ratios of calcium to lanthanum (Ca-to-La) were synthesized by co-precipitation method. The synthesized solid $\mathrm{CaO}$ ï $\mathrm{La} 2 \mathrm{O} 3$ mixed metal oxide catalysts were utilized in transesterification of Jatropha curcus oil as feedstock to produce biodiesel. Under the optimized conditions at 65 ${ }^{\circ} \mathrm{C}$, $4 \%$ catalyst dose with $24: 1 \mathrm{MeOH}$ to Jatropha oil molar ratio, the transesterification reaction exhibited $86.51 \%$ of biodiesel yield. The prepared catalysts were characterized using various techniques such as X-ray diffraction (XRD), nitrogen sorption with Brunauerï Emmerï Teller (BET) method, temperature-programmed desorption of $\mathrm{CO} 2$ (CO2-TPD) and scanning electron microscopy (SEM). Influence of Ca-to-La atomic ratio in the mixed metal oxide catalyst, catalyst amount, methanol to oil molar ratio, reaction time, different oils on the fatty acid methyl ester (FAME) yield were appraised. Different catalyst regeneration procedures were also performed to investigate the reusability of the $\mathrm{CaO}$ ï $\mathrm{La} 2 \mathrm{O} 3$ catalyst.
\end{abstract}

Keyword: Biodiesel production; Jatropha curcas; Heterogeneous catalyst; Transesterification; CaOï La2O3 